\title{
CHAPTER APPENDIXES
}

9.1. Specimens from Porcupine Cave showing taphonomic or paleopathological modification 90

11.1. Amphibian and reptile specimens recovered from Porcupine Cave 124

13.1. Carnivore specimens from Porcupine Cave 149

14.1. Ochotona specimens from Porcupine Cave 160

17.1. List of specimens examined for the four most abundant sciurids studied 187
18.1. Specimens of Neotoma from the Pit 204

19.1. Specimens of arvicoline rodents from Porcupine Cave 220

21.1. Artiodactyl remains from Porcupine Cave 291

22.1. Repository numbers of all specimens used in the Badger Room analyses 316

25.1. Listing of analyzed Marmota specimens 340 
This page intentionally left blank 